\title{
Substrate integrated waveguide bandpass filter for short range device application using rectangular open loop resonator
}

\author{
Dian Widi Astuti, Rizki Ramadhan Putra, Muslim, Mudrik Alaydrus \\ Department of Electrical Engineering, Universitas Mercu Buana, Indonesia
}

\begin{tabular}{l}
\hline \hline Article Info \\
\hline Article history: \\
Received Mar 21, 2019 \\
Revised Mar 25, 2021 \\
Accepted Apr 10, 2021 \\
\hline
\end{tabular}

\section{Keywords:}

Bandpass filter

Microstrip filter

Rectangular open loop

resonator

Short range device

SIW filter

\begin{abstract}
The substrate integrated waveguide (SIW) structure is the candidate for many application in microwave, terahertz and millimeter wave application. It because of SIW structure can integrate with any component in one substrate than others structure. A kind components using SIW structure is a filter component, especially bandpass filter. This research recommended SIW bandpass filter using rectangular open loop resonator for giving more selectivity of filter. It can be implemented for short range device (SRD) application in frequency region 2.4-2.483 GHz. Two types of SIW bandpass filter are proposed. First, SIW bandpass filter is proposed using six rectangular open loop resonators while the second SIW bandpass filter used eight rectangular open loop resonators. The simulation results for two kinds of the recommended rectangular open loop resonators have insertion loss $\left(\mathbf{S}_{21}\right.$ parameter) below $2 \mathrm{~dB}$ and return loss ( $\mathrm{S}_{11}$ parameter) more than $10 \mathrm{~dB}$. Fabrication of the recommended two kind filters was validated by Vector Network Analyzer. The measurement results for six rectangular open loop resonators have $1.32 \mathrm{~dB}$ for $\mathrm{S}_{21}$ parameter at $2.29 \mathrm{GHz}$ while the $\mathrm{S}_{11}$ parameter more than $18 \mathrm{~dB}$ at $2.26 \mathrm{GHz}-2.32 \mathrm{GHz}$. While the measurement results has good agreement for eight rectangular open loop resonators. It has $\mathrm{S}_{21}$ below $2.2 \mathrm{~dB}$ at $2.41-2.47 \mathrm{GHz}$ and $\mathrm{S}_{11} 16.27 \mathrm{~dB}$ at $2.38 \mathrm{GHz}$ and 11.5 $\mathrm{dB}$ at $2.47 \mathrm{GHz}$.
\end{abstract}

This is an open access article under the CC BY-SA license.

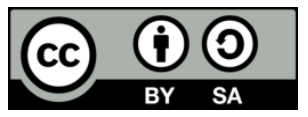

\section{Corresponding Author:}

Dian Widi Astuti

Department of Electrical Engineering

Universitas Mercu Buana

Meruya Selatan No. 1 Kembangan Kebun Jeruk, Jakarta, Indonesia

Email: dian.widiastuti@mercubuana.ac.id

\section{INTRODUCTION}

The rapid growth of wireless communication systems leads to a crowded occupation of the electromagnetic spectrum. In order to avoid possible interferences, the availability of high selective filters is necessary. Lowpass and bandpass filters with high selectivity have been presented in [1]-[4]. By using Hilbert curve ring and sierpinski carpet defected ground structure (DGS) in paper [1], the compactness and selectivity were achieved. Selectivity of filter can also be achieved by coupling between two resonators as shown in [2]-[4]. Resonator coupling occurs between two parallel resonators closely. The parallel coupled resonator in [2] are quite long enough then the single resonator is made become rectangular open loop resonator as shown in [3]. By using material with low loss dielectric and high permittivity can improve $\mathbf{S}_{21}$, selectivity and compact of filter as shown in [4].

Compact filter can be achieved by using substrate integrated waveguide (SIW) structure because many components can be implemented in one substrate, known system on substrate (SoS). SIW also offers good performance such as the low loss, light weight and easy to construct. The first filter in SIW structure 
was inductive post filter by using three-pole Chebyshev filter to give low $S_{21}$ and better $S_{11}$ values [5]. For giving more compact filter, DGS has been successfully implemented in the SIW structure as presented in [6], [7]. The DGS is scratched at the upper metal cover with three cascaded cells to give more selective.

Complimentary split ring resonator (CSRR) can be categorized as metamaterial structure, has been analyzed in [8]-[10] to give compact and sharp rejection besides DGS [11]. In [8], several CSRR is used to form stopband with very sharp rejection in wideband. The internal and external coupling are extracted by $Q$ factor in the dominant mode at [9], [10]. Unlike the conventional SIWs, the passbass located below the dominant frequency.

This research proposed a compact and sharp selectivity bandpass filter by using rectangular open loop resonator. The rectangular open loop resonator will generate coupling between two resonators and selectivity will be archived. The filter design is for SRD application at $2.44 \mathrm{GHz}$ as the frequency center. Overall, this research is presented as follow: research method for SIW and rectangular open loop for six and eight resonators in section 2. Meanwhile in section 3 gives the simulation and measurement results discussion. Some parametric studies are offered to give better understanding of the rectangular open loop resonator characteristic in SIW filter. Finally, this research is closed by conclusion in section 4 .

\section{RESEARCH METHOD}

\subsection{Substrate integrated waveguide}

SIW was introduced firstly by name of post wall waveguide [12] or laminated waveguide [13] but right now SIW is more popular [14]. Wu et al. developed SIW so that SIW can be implemented to many kinds of components even active or passive components. SIW can be implemented by using SIW structure such as filter [5], [15], amplifier [16], antenna [17]-[20], filtering antenna [21], circulator [22], coupler [23], oscillator [24], mixer [25] and many more.

SIW structure is applied as the basic of transmission line consists of the parallel metal holes as shown in Figure 1. It required the lowest frequency that can transmit to the SIW structure. The lowest frequency can be named as the dominant frequency, $f_{m n l}$. The dominant frequency is obtained by the equation for the rectangular waveguide as (1),

$$
f_{m n l}=\frac{c}{2 \pi \sqrt{\mu_{r} \varepsilon_{r}}} \sqrt{\left(\frac{m \pi}{a}\right)^{2}+\left(\frac{n \pi}{b}\right)^{2}+\left(\frac{l \pi}{e}\right)^{2}}
$$

where $m, n$ and $l$ are the integer number of differences in the standing wave pattern for the rectangular coordinate respectively [26]. Parameter $a, b, e$ are the equivalent broadness, thickness and extent of the cavity. Because of the ratio between broadness and thickness substrate are too high, only $\mathrm{TE}_{\mathrm{m} 01}$ modes can propagate in the SIW structure, $n=0$. The lowest mode for transversal electrical (TE) mode was TE 101 . It should be implemented for miniaturization design. The configuration for metallized holes have to be satisfied by $2 p / d<5$ and $d / \lambda_{0} \leq 0.1$ where the metallized hole diameter $d$ the center distance between two adjacent metallized holes $p$ and $\lambda_{0}$ is the wavelength at the free to air condition [27]. The SIW transmission line is feed by tapper with the minimum length is quarter wavelength of the quasi-TE mode.

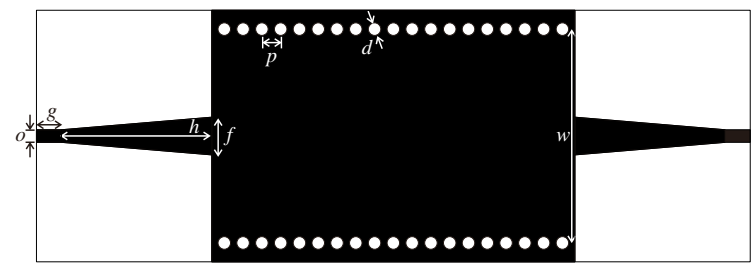

(a)

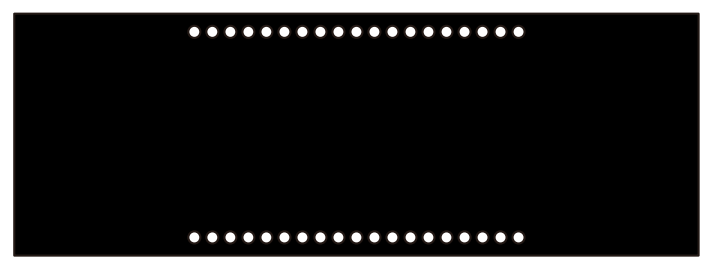

(b)

Figure 1. Dominant frequency design; (a) The upper layer, (b) The bottom layer, the black color is the copper layer

Rogers RO3210 with substrate thickness $0.64 \mathrm{~mm}$, tangent loss $(\delta) 0.003$, the relative permittivity constant $\left(\varepsilon_{r}\right) 10.2$ is used in this design in order to get more compact bandpass filter. Figure 1 shows the dominant frequency design. Unlike usual, in this design used dominant frequency higher than the bandpass frequency. The dominant frequency simulation is achieved by using Ansys HFSS. 


\subsection{Six rectangular open loop resonators}

The designed filter consists several rectangular open loop resonators on the upper layer to disturb electric current. The six rectangular open loop resonators are scratched out on the upper layer. The single rectangular open loop resonator is design base on [4] and duplicate six times as displayed in Figure 2. The length, width, gap of the rectangular open loop resonator are regulated to suitable with resonance frequency. The parameter variable for six rectangular open loop resonators is tabled in Table 1.

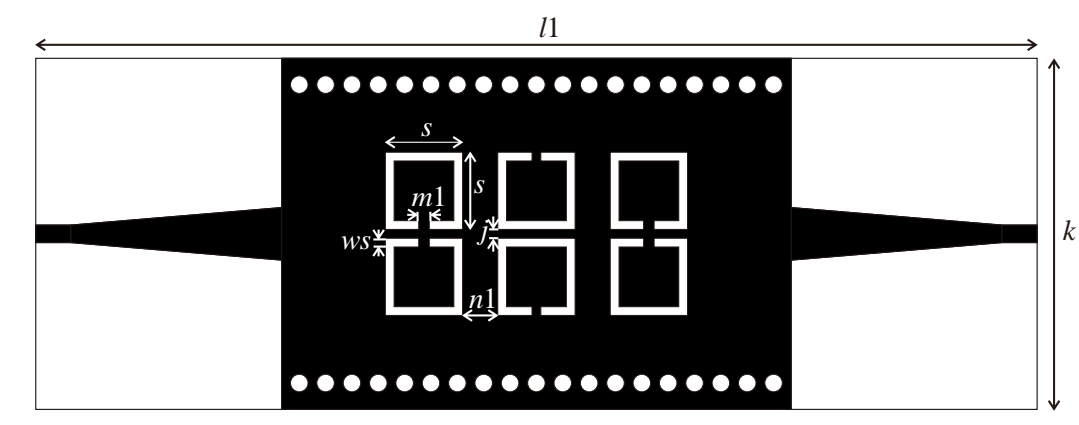

Figure 2. Six rectangular open loop resonators design

Table 1. Dimension of six rectangular open loop resonators (in $\mathrm{mm}$ )

\begin{tabular}{cccc}
\hline parameter & unit & parameter & unit \\
\hline$s$ & 4.4 & $k$ & 20 \\
$w s$ & 0.5 & $l 1$ & 57 \\
$d$ & 1 & $m 1$ & 0.5 \\
$f$ & 3 & $n 1$ & 2 \\
$g$ & 2 & $p$ & 1.5 \\
$h$ & 12 & $w$ & 17 \\
$j$ & 0.5 & $o$ & 1 \\
\hline
\end{tabular}

\subsection{Eight Rectangular open loop resonators}

Same as before, eight rectangular open loop resonators are constructed by a single rectangular open loop resonator. Eight rectangular open loop resonators gives narrow bandwidth, sharp selectivity and better insertion values even though the second resonance frequency will change closer. Eight rectangular open loop resonator design is displayed in Figure 3. The variable parameter $n 1$ in eight rectangular open loop resonators is $2.5 \mathrm{~mm}$ while the others variable parameters are same with Table 1 .

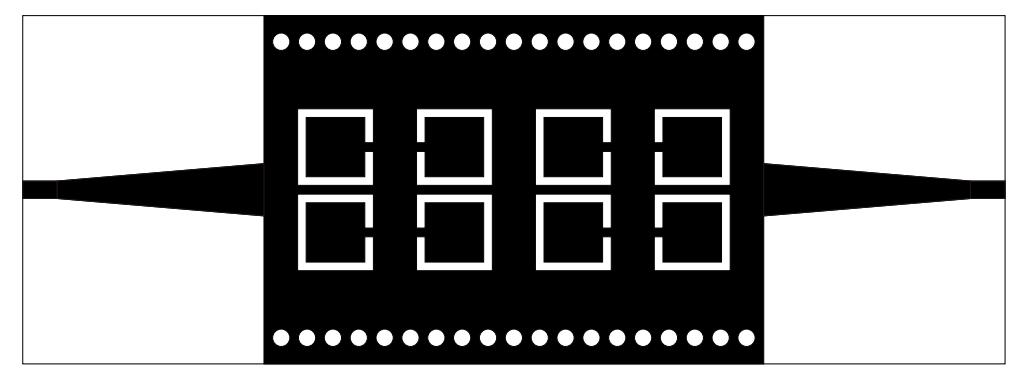

Figure 3. Eight rectangular open loop resonators design

\section{RESULTS AND DISCUSSION}

\subsection{Simulation}

The simulation variables of $j$ dan $n 1$ are shown in Figure 4. Some parametric studies was given to give more understanding about coupling between two or more rectangular open loop resonator. Figure 4(a) shown the simulation of variable $j$, separation between four rectangular open loop resonators up and down. It shown if the $j$ increases from $0.3 \mathrm{~mm}$ to $0.7 \mathrm{~mm}$ than the resonance frequency changes to the higher frequency and the $S_{11}$ will be low. Separation between rectangular open loop left and right was notified as 
variable $n 1$. If $n 1$ variable increases from $1 \mathrm{~mm}$ to $3 \mathrm{~mm}$ than narrow bandwidth will be achieved and $\mathrm{S}_{11}$ will be low as shown in Figure 4(b). Figure 4(c) shows if the distance between $n 1$ and $j$ are small than bandwidth will wider than distance between $n 1$ and $j$ are far away. Table 2 to Table 4 summarize parametric studies of variables $n 1$ and $j$ for six rectangular open loop resonators.

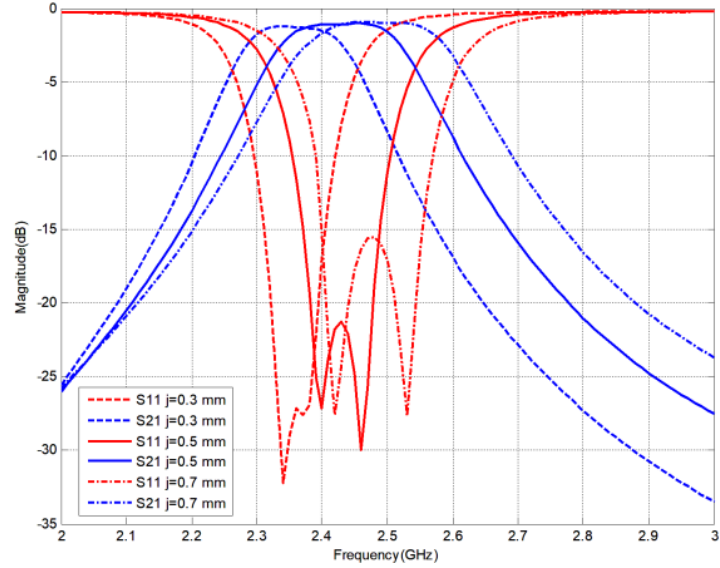

(a)

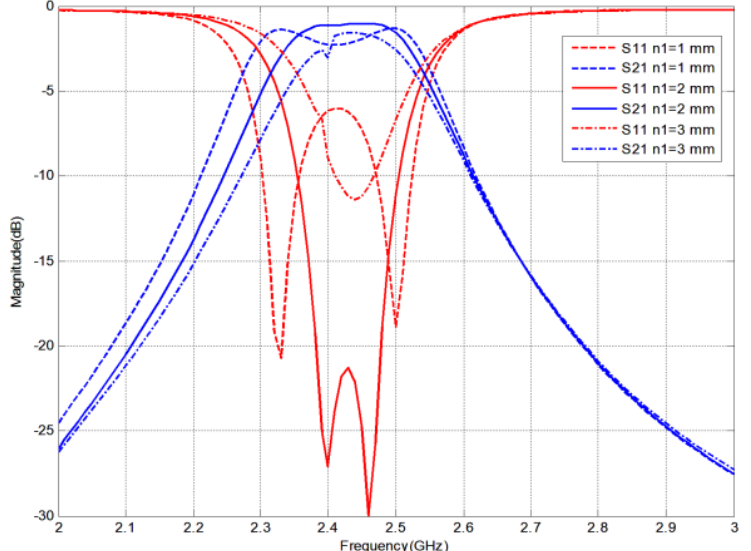

(b)

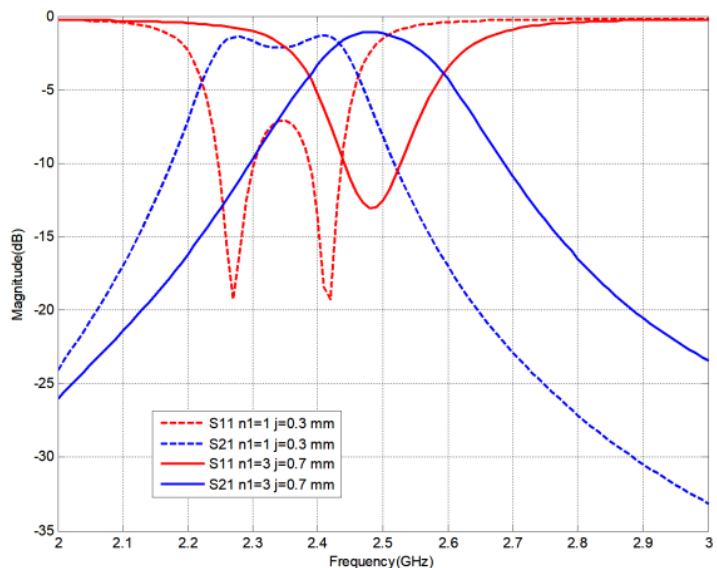

(c)

Figure 4. S-parameter simulation for six rectangular open loop resonator as variable; (a) $j$, (b) $n 1$, (c) $n 1$ and $j$

Table 2. Simulation results of variable $j$ for six rectangular open loop resonator (in $\mathrm{mm}$ )

\begin{tabular}{ccccc}
\hline$j$ & $\mathrm{~S}_{21}(\mathrm{~dB})$ & $\mathrm{S}_{11}(\mathrm{~dB})$ & $\begin{array}{c}\text { Center } \\
\text { Frequency } \\
(\mathrm{GHz})\end{array}$ & $\begin{array}{c}\text { Bandwidth } \\
(\mathrm{MHz})\end{array}$ \\
\hline 0.3 & 1.68 & 32.2 & 2.36 & 100 \\
0.5 & 1.07 & 29.78 & 2.43 & 140 \\
0.7 & 1.44 & 27.65 & 2.48 & 160 \\
\hline
\end{tabular}

Table 3. Simulation results of variable $j$ for six rectangular open loop resonator (in $\mathrm{mm}$ )

\begin{tabular}{ccccc}
\hline$n 1$ & $\mathrm{~S}_{21}(\mathrm{~dB})$ & $\mathrm{S}_{11}(\mathrm{~dB})$ & $\begin{array}{c}\text { Center } \\
\text { Frequency } \\
(\mathrm{GHz})\end{array}$ & $\begin{array}{c}\text { Bandwidth } \\
(\mathrm{MHz})\end{array}$ \\
\hline 1 & 1.44 & 20.71 & 2.42 & 190 \\
2 & 1.07 & 29.78 & 2.43 & 140 \\
3 & 1.58 & 11.39 & 2.44 & 120 \\
\hline
\end{tabular}

Table 4. Simulation results of variable $j$ and $n 1$ for six rectangular open loop resonator (in mm)

\begin{tabular}{cccccc}
\hline$j$ & $n 1$ & $\mathrm{~S}_{21}(\mathrm{~dB})$ & $\mathrm{S}_{11}(\mathrm{~dB})$ & Center Frequency $(\mathrm{GHz})$ & Bandwidth $(\mathrm{MHz})$ \\
\hline 0.3 & 1 & 1.36 & 19.28 & 2.35 & 150 \\
0.7 & 3 & 1.95 & 13.07 & 2.47 & 70 \\
\hline
\end{tabular}

Figure 5 gives the simulation results for variables $j$ and $n 1$ for eight rectangular open loop resonator. If variable $j$ increases from $0.3 \mathrm{~mm}$ to $0.7 \mathrm{~mm}$ the bandwidth will be wide, the $\mathrm{S}_{11}$ are quite same and still below at $10 \mathrm{~dB}$ as presented in Figure 5(a). While in Figure 5(b) if variable $n 1$ decreases from $3 \mathrm{~mm}$ to $2 \mathrm{~mm}$ 
the passband will change to the lower frequency and the $S_{11}$ gets low until $8.52 \mathrm{~dB}$. Figure 5(c) shows if the distance between $n 1$ and $j$ are far away than the narrow bandwidth will be achieve and the passband will change to the higher frequency. It is vice versa for the condition if the distance between variables $n 1$ and $j$ are small. The detail summary of parametric studies are shown in Table 5 to Table 7.

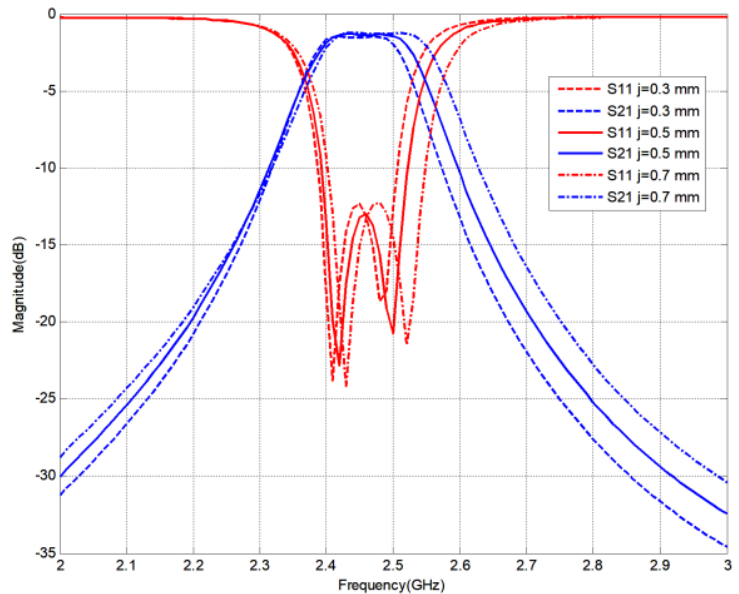

(a)

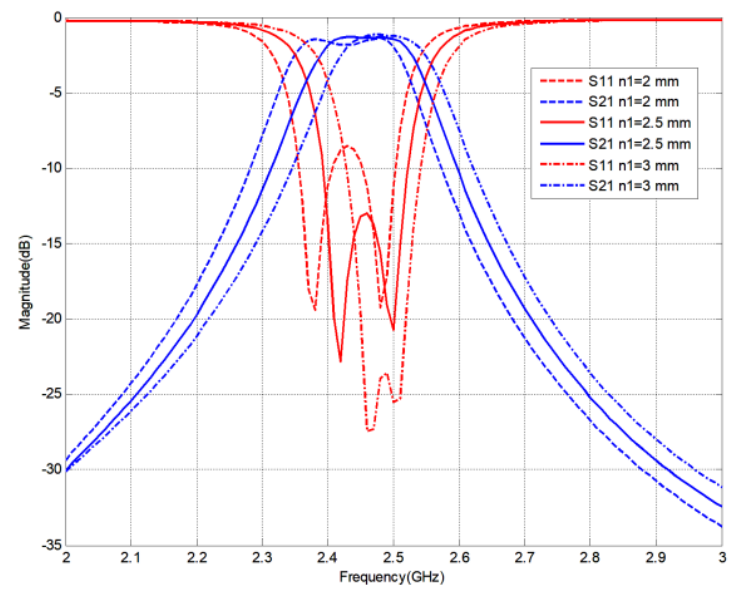

(b)

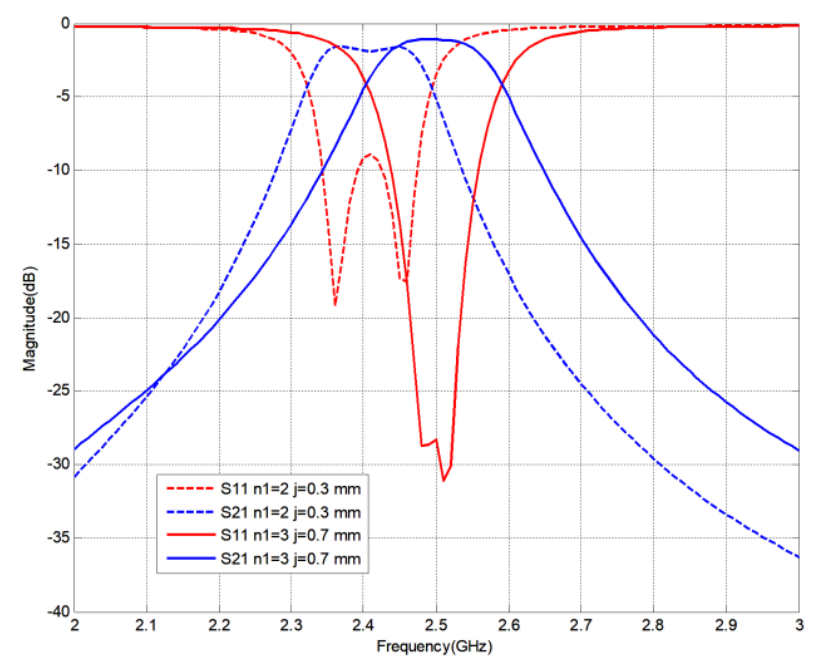

(c)

Figure 5. S-parameter simulation for eight rectangular open loop resonator as variable; (a) $j$, (b) $n 1$, (c) $n 1$ and $j$

Table 5. Simulation results of variable $j$ for eight rectangular open loop resonator (in $\mathrm{mm}$ )

\begin{tabular}{ccccc}
\hline$j$ & $\mathrm{~S}_{21}(\mathrm{~dB})$ & $\mathrm{S}_{11}(\mathrm{~dB})$ & $\begin{array}{c}\text { Center } \\
\text { Frequency } \\
(\mathrm{GHz})\end{array}$ & $\begin{array}{c}\text { Bandwidth } \\
(\mathrm{MHz})\end{array}$ \\
\hline 0.3 & 1.71 & 23.79 & 2.45 & 100 \\
0.5 & 1.37 & 22.81 & 2.46 & 110 \\
0.7 & 1.41 & 24.19 & 2.48 & 110 \\
\hline
\end{tabular}

Table 6. Simulation results of variable $n 1$ for eight rectangular open loop resonator (in $\mathrm{mm}$ )

\begin{tabular}{ccccc}
\hline$n 1$ & $\mathrm{~S}_{21}(\mathrm{~dB})$ & $\mathrm{S}_{11}(\mathrm{~dB})$ & $\begin{array}{c}\text { Center } \\
\text { Frequency } \\
(\mathrm{GHz})\end{array}$ & $\begin{array}{c}\text { Bandwidth } \\
(\mathrm{MHz})\end{array}$ \\
\hline 2 & 1.55 & 19.4 & 2.43 & 120 \\
2.5 & 1.37 & 22.81 & 2.46 & 110 \\
3 & 1.58 & 27.43 & 2.49 & 90 \\
\hline
\end{tabular}

Table 7. Simulation results of variable $c$ and $n$ for eight rectangular open loop resonator (in mm)

\begin{tabular}{cccccc}
\hline$j$ & $n 1$ & $\mathrm{~S}_{21}(\mathrm{~dB})$ & $\mathrm{S}_{11}(\mathrm{~dB})$ & Center Frequency $(\mathrm{GHz})$ & Bandwidth $(\mathrm{MHz})$ \\
\hline 0.3 & 2 & 1.58 & 19.19 & 2.41 & 100 \\
0.7 & 3 & 1.4 & 31.12 & 2.5 & 90 \\
\hline
\end{tabular}


Comparison between six and eight rectangular open loop resonator is given in Figure 6. It can be analyzed that eight rectangular open loop resonators give narrow bandwidth than six rectangular open loop resonators. The $S_{21}$ at six rectangular open loop resonator is better than the $S_{21}$ at eight rectangular open loop resonator. Likewise, the $S_{11}$ value will be higher if the $S_{21}$ value is small.

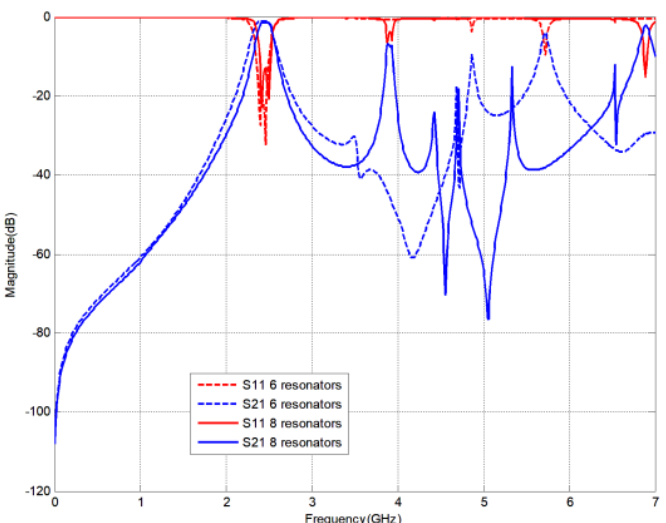

(a)

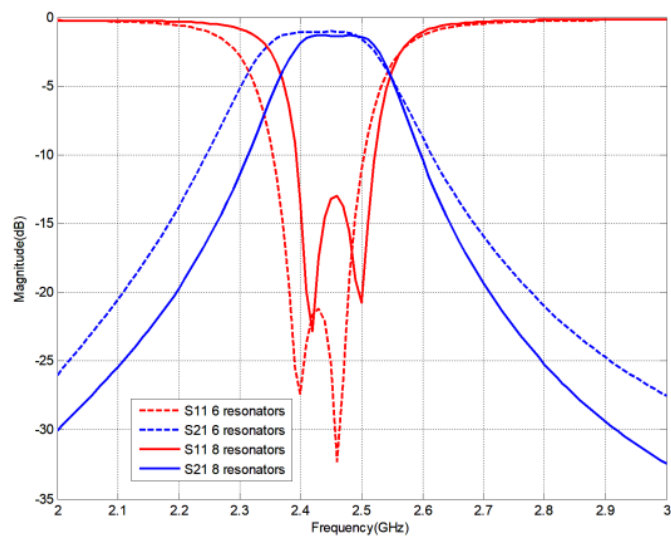

(b)

Figure 6. S-parameter comparison six and eight rectangular open loop resonator; (a) Wideband, (b) Narrow band

\subsection{Measurement}

Figure 7 shows the fabrication of dominant frequency, six and eight rectangular open loop resonator in SIW structure. Figure 7(a) is the dominant frequency fabrication while Figure 7(b) and 7(c) are six and eight rectangular open loop resonators. The resonators was scratched at the upper layer. The ground layer is same for three fabrications as shown in Figure 7(d).

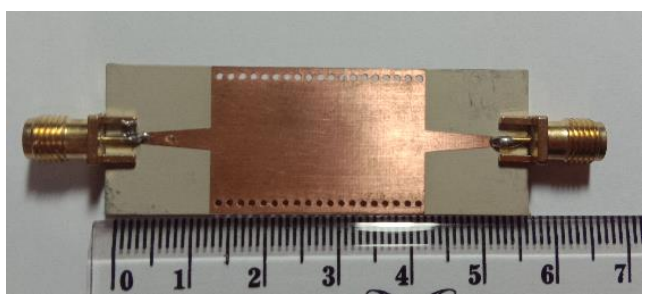

(a)

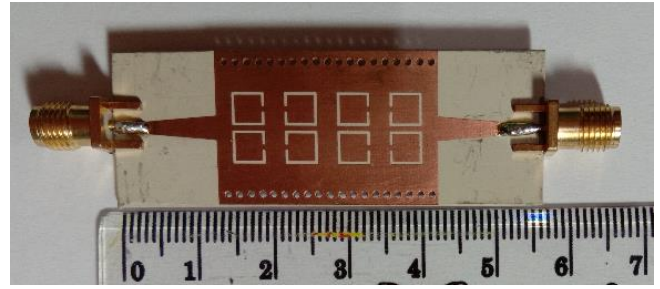

(c)

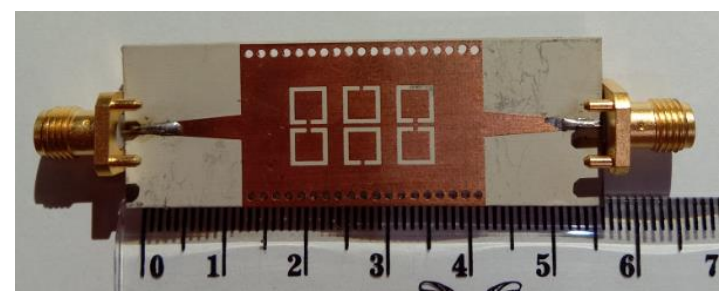

(b)

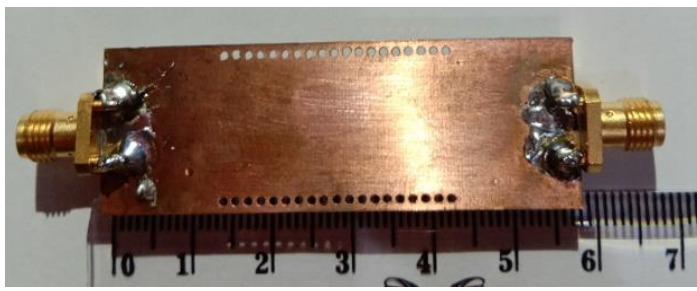

(d)

Figure 7. Fabrication photograph of, (a) The upper layer dominant frequency, (b) The upper layer six rectangular open loop resonators, (c) The upper layer eight rectangular open loop resonators, (d) The ground

layer for dominant frequency, six rectangular open loop resonators and eight rectangular open loop resonators

As mentioned before that the dominant frequency was higher than bandpass frequency. The measurement of dominant frequency fabrication as shows in Figure 8. It prove the cut frequency at around $3 \mathrm{GHz}$. 


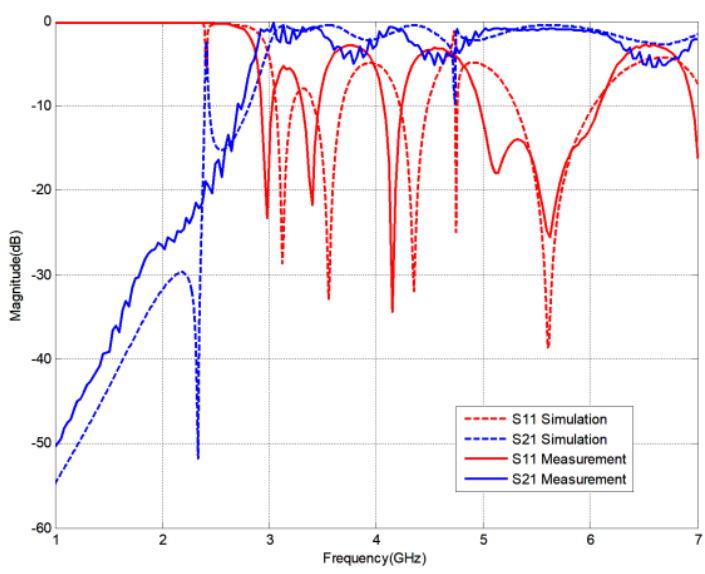

Figure 8. S-parameter simulation and measurement results from dominant frequency

For six rectangular open loop resonators, simulation results are presented in Figure 9(a) for narrow band and Figure 9(b) for wideband. The simulation for $\mathrm{S}$ parameter gives the $\mathrm{S}_{21}$ values $1.11 \mathrm{~dB}$ at $2.4 \mathrm{GHz}$ and $1.19 \mathrm{~dB}$ at $2.483 \mathrm{GHz}$. The $83 \mathrm{MHz}$ bandwidth range is achieved by simulation result which it can be applied for SRD application with $2.44 \mathrm{GHz}$ frequency center. While the $\mathrm{S}_{11}$ values show more than $20 \mathrm{~dB}$ for frequency region at $2.38 \mathrm{GHz}$ until $2.48 \mathrm{GHz}$. By using VNA, the fabrication filter is validated. The measurement displays the frequency changing through a low frequency where the frequency center become $2.3 \mathrm{GHz}$. It means that the difference is around $140 \mathrm{MHz}$. The discrepancy occurs because of inaccuracy fabrication process in mm-scales and ports connection. The $\mathrm{S}_{21}$ value becomes increase to a $1.32 \mathrm{~dB}$ at $2.29 \mathrm{GHz}$. The $\mathrm{S}_{11}$ values are still over than $18 \mathrm{~dB}$ at frequency region $2.26-2.32 \mathrm{GHz}$. The discrepancy usually occurs in the measurement results but overall the simulation results and measurement results give an acceptable values. In Figure 9(b) shows a wide bandstop until $5 \mathrm{GHz}$.

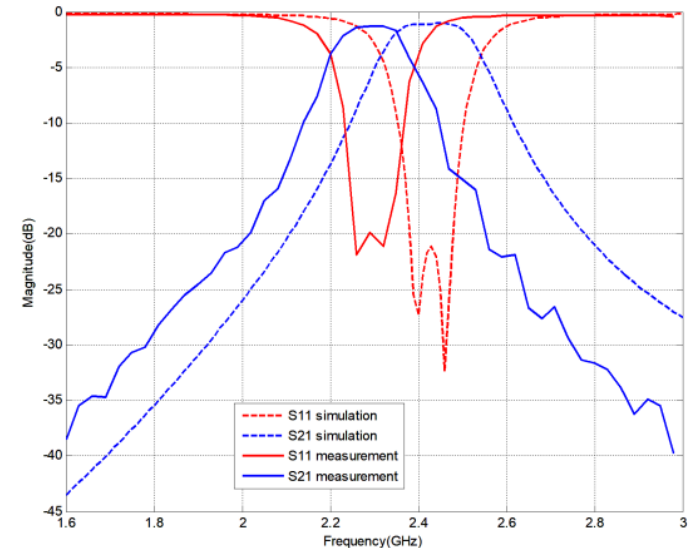

(a)

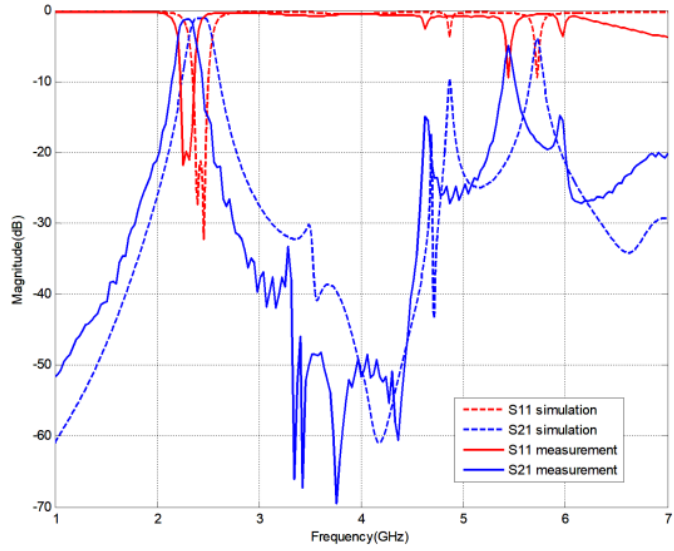

(b)

Figure 9. Simulation and measurement results for six rectangular open loop resonator as, (a) Narrow band, (b) Wideband

Relationship between simulation and measurement results is compared for eight rectangular open loop resonators as shown in Figure 10. Figure 10(a) is for the narrow band while Figure 10(b) is for wideband. The simulation results have $S_{21} 1.88 \mathrm{~dB}$ at $2.4 \mathrm{GHz}$ and $1.34 \mathrm{~dB}$ at $2.48 \mathrm{GHz}$. The $\mathrm{S}_{11}$ values are $22.81 \mathrm{~dB}$ at $2.42 \mathrm{GHz}$ and $20.72 \mathrm{~dB}$ at $2.5 \mathrm{GHz}$. Overall, the $\mathrm{S}$-parameter simulation for eight rectangular open loop resonator are acceptable because of the $S_{11}$ values are still below $10 \mathrm{~dB}$ for $2.4 \mathrm{GHz}$ until $2.483 \mathrm{GHz}$. While the measurement results show $\mathrm{S}_{21} 1.65 \mathrm{~dB}$ at $2.41 \mathrm{GHz}$ and $2.15 \mathrm{~dB}$ at $2.47 \mathrm{GHz}$. The $\mathrm{S}_{11}$ are $16.27 \mathrm{~dB}$ at $2.38 \mathrm{GHz}$ and $11.5 \mathrm{~dB}$ at $2.47 \mathrm{GHz}$. The differentiation among simulation and measurement results appear because of soldering connector or fabrication process. Generally, the validation for $\mathrm{S}$ 
parameter still have acceptable values because $S_{21}$ still below than $3 \mathrm{~dB}$ even $\mathrm{S}_{11}$ still more than $7 \mathrm{~dB}$. The second bandpass are come up to the first bandpass.

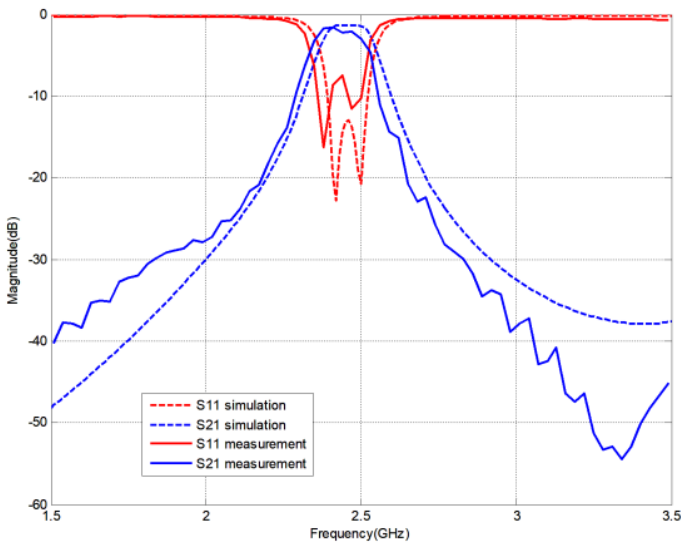

(a)

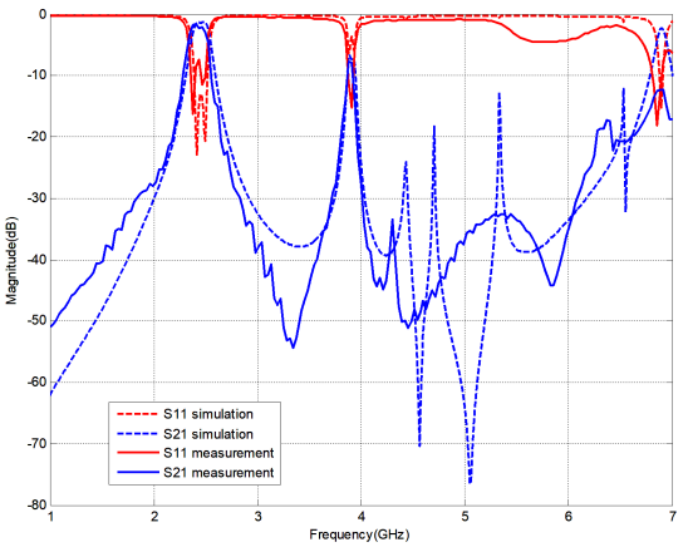

(b)

Figure 10. Simulation and measurement results for eight rectangular open loop resonators as;

(a) Narrow band, (b) Wideband

\section{CONCLUSION}

A substrate integrated waveguide (SIW) bandpass filter using complementary split rectangular resonator has been designed, fabricated and validated for short range device (SRD) application at $2.44 \mathrm{GHz}$ frequency center. The simulation and measurement results give good values for $\mathrm{S}$ parameter event though the discrepancy occurs. Mostly, it always happens due to soldering connector or fabrication process.

\section{ACKNOWLEDGEMENTS}

The authors are very grateful to Indonesia Ministry of Research, Technology and Higher Education, RISTEKDIKTI for supporting and funding this research in PDUPT scheme 2018-2019 under contract number 02-5/006/HD-SPK/III/2019.

\section{REFERENCES}

[1] D. W. Astuti, I. Wahyuni, and M. Alaydrus, "Lowpass Filter with Hilbert Curve Ring and Sierpinski Carpet DGS," TELKOMNIKA Telecommunication Computing Electronics and Control, vol. 16, no. 3, pp. 1092-1100, 2018, doi: 10.12928/TELKOMNIKA.v16i3.7722.

[2] M. Alaydrus, "Designing microstrip bandpass filter at $3.2 \mathrm{GHz}$," International Journal on Electrical Engineering and Informatics, vol. 2, no. 2, pp. 71-83, 2010.

[3] M. Alaydrus, D. Widiastuti, and T. Yulianto, "Designing Cross-Coupled Bandpass Filters with Transmission Zeros in Lossy Microstrip," in International Conference on Information Technology and Electrical Engineering, 2010, pp. 277-280.

[4] D. W. Astuti and M. Alaydrus, "A Bandpass Filter Based on Rectangular Open Loop Resonators at $2.45 \mathrm{GHz}$," in IEEE International Conference on Instrument, Communications, Information Technology and Biomedical Engineering, 2013, no. 1, pp. 147-151.

[5] D. Deslandes and K. Wu, "Single-substrate integration technique of planar circuits and waveguide filters," IEEE Transactions on microwave theory and Techniques, vol. 51, no. 2, pp. 593-596, 2003, doi: 10.1109/TMTT.2002.807820.

[6] D. W. Astuti, A. Jubaidilah, and M. Alaydrus, "Substrate integrated waveguide bandpass filter for VSAT downlink," in QiR 2017 - 2017 15th International Conference on Quality in Research (QiR): International Symposium on Electrical and Computer Engineering, Dec. 2017, vol. 2017, pp. 101-105.

[7] D. W. Astuti, M. W. Adhitama, and T. A. Pahlevi, "Substrate Integrated Waveguide Filter with A Slot in The Middle of Defected Ground Structure," 2018 10th International Conference on Information Technology and Electrical Engineering (ICITEE), 2018, vol. 2, pp. 22-25.

[8] W. Che, C. Li, K. Deng, and L. Yang, "A Novel Bandpass Filter Based on Complementary Split Rings Resonators and Substrate Integrated Waveguide," Microwave and Optical Technology Letters, vol. 50, no. 3, pp. 699-701, 2008, doi: 10.1002/mop.23182. 
[9] Q. L. Zhang, W. Y. Yin, S. He, and L. S. Wu, "Compact substrate integrated waveguide (SIW) bandpass filter with complementary split-ring resonators (CSRRs)," IEEE microwave and wireless components letters, vol. 20, no. 8, pp. 426-428, 2010, doi: 10.1109/LMWC.2010.2049258.

[10] F. Furqan, S. Attamimi, A. Adriansyah, and M. Alaydrus, "Bandpass filter based on complementary split ring resonators at X-Band," Indonesian Journal of Electrical Engineering and Computer Science (IJEECS), vol. 13, no. 1, pp. 243-248, 2019.

[11] A. Belmajdoub, A. Boutejdar, A. El Alami, S. D. Bennani, and M. Jorio, "Design and optimization of a new compact 2.4 GHz-bandpass filter using DGS technique and U-shaped resonators for WLAN applications," TELKOMNIKA Telecommunication Computing Electronics and Control, vol. 17, no. 3, pp. 1081-1089, 2019, doi: 10.12928/TELKOMNIKA.v17i3.10913.

[12] J. Hirokawa and M. Ando, "Single-Layer Feed Waveguide Consisting of Posts for Plane TEM Wave Excitation in Parallel Plates," IEEE Trans. Antennas Propag., vol. 46, no. 5, pp. 625-630, 1998.

[13] H. Uchimura, T. Takenoshita, and M. Fujii, "Development of a 'laminated waveguide," IEEE Trans. Microw. Theory Tech., vol. 46, no. 12, pp. 2438-2443, 1998.

[14] M. Bozzi, A. Georgiadis, and K. Wu, "Review of substrate-integrated waveguide circuits and antennas," IET Microwaves, Antennas Propag., vol. 5, no. 8, pp. 909-920, 2011.

[15] X. Chen and K. Wu, "Substrate Integrated Waveguide Cross-Coupled Filter With Negative Coupling Structure," IEEE Trans. Microw. Theory Tech, vol. 56, no. 1, pp. 142-149, 2008.

[16] M. Abdolhamidi and M. Shahabadi, "X-Band Substrate Integrated Waveguide Amplifier," IEEE Microw. Wirel. Components Lett., vol. 18, no. 12, pp. 815-817, 2008.

[17] D. Chaturvedi and S. Raghavan, "A Half-Mode SIW Cavity-Backed Semi-Hexagonal Slot Antenna for WBAN Application," IETE J. Res., pp. 1-7, Apr. 2018.

[18] G. Q. Luo, Z. F. Hu, L. X. Dong, and L. L. Sun, "Planar slot antenna backed by substrate integrated waveguide cavity," IEEE Antennas Wirel. Propag. Lett., vol. 7, pp. 236-239, 2008.

[19] D. W. Astuti and E. T. Rahardjo, "Size Reduction of Substrate Integrated Waveguide Cavity Backed U-Slot Antenna," 2018 IEEE Indian Conf. Antennas Propogation, vol. 2, no. 1, pp. 1-4, 2018.

[20] D. W. Astuti and E. T. Rahardjo, "Size Reduction of Cavity Backed Slot Antenna using Half Mode Substrate Integrated Waveguide Structure," 4th Int. Conf. Nano Electron. Res. Educ. Towar. Adv. Imaging Sci. Creat. ICNERE 2018, 2018, pp. 1-4.

[21] O. A. Nova, J. C. Bohórquez, N. M. Peña, G. E. Bridges, L. Shafai, and C. Shafai, "Filter-antenna module using substrate integrated waveguide cavities," IEEE Antennas Wirel. Propag. Lett., vol. 10, pp. 59-62, 2011.

[22] W. D'Orazio and K. Wu, "Substrate-integrated-waveguide circulators suitable for millimeter-wave integration," IEEE Trans. Microw. Theory Tech., vol. 54, no. 10, pp. 3675-3679, 2006.

[23] Z. C. Hao, W. Hong, J. X. Chen, H. X. Zhou, and K. Wu, "Single-layer substrate integrated waveguide directional couplers," IEE Proceedings-Microwaves, Antennas Propag., vol. 153, no. 5, pp. 426-431, 2006.

[24] C. Zhong, J. Xu, Z. Yu, and Y. Zhu, "Ka-Band Substrate Integrated Waveguide Gunn Oscillator," IEEE Microw. Wirel. Components Lett., vol. 18, no. 7, pp. 461-463, 2008.

[25] J. X. Chen, W. Hong, Z.-C. Hao, H. Li, and K. Wu, "Development of a Low Cost Microwave Mixer Using a Broad-band Substrate Integrated Waveguide (SIW) Coupler," IEEE Microw. Wirel. Components Lett., vol. 16, no. 2, pp. 84-86, 2006.

[26] D. M. Pozar, "Microwave Engineering, 4th Edition,” John Wiley \& Sons, Inc., pp. 1-756, 2012.

[27] F. X. and K. Wu, "Guided-wave and leakage characteristics of substrate integrated waveguide," IEEE Trans. Microw. Theory Tech, vol. 53, no. 5, pp. 66-73, 2005.

\section{BIOGRAPHIES OF AUTHORS}

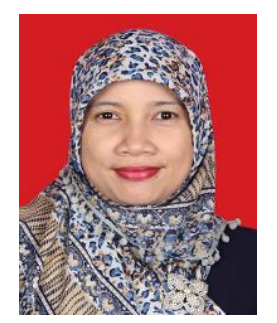

Dian Widi Astuti was born in Jakarta, Indonesia. She received the B. Eng and M. Eng from Universitas Mercu Buana, Jakarta-Indonesia. Since 2012, she has been a lecturer and joint electromagnetic and telecommunication Laboratory in the Universitas Mercu Buana, Jakarta. Her current research interest include microwave, millimeter-wave passive components design. She is currently working toward Ph.D degree at Universitas Indonesia, Indonesia.

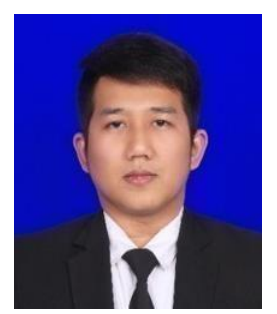

Rizki Ramadhan Putra earned his Bachelor's degree from Department of Electrical Engineering, Mercubuana University Jakarta in 2018. He earned his Bachelor's degree after designing Band Pass Filter with Substrate Integrated Waveguide and Complementary Split Ring Resonator method. During that time, he also working on PT Indosat as Field and Network Engineer which has responsibility of Operating and Maintaining Indosat's Jabotabek Backbone. 


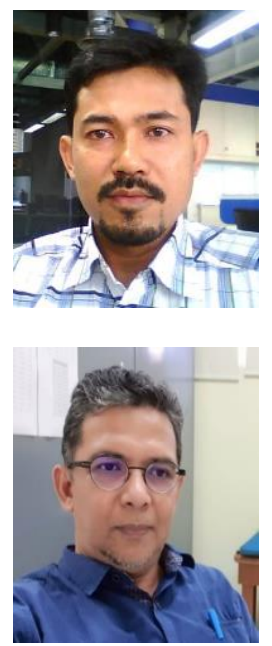

Muslim received the B.Eng and M. Eng from Universitas Mercu Buana, Jakarta-Indonesia. He was practitioner engineering in Broadcasting television from 1994 until now. He joint as a Lecture in Universitas Mercu Buana from 2015. He current research interest include trouble shooting and microwave passive components design.

Mudrik Alaydrus received the Dipl.-Ing. and Dr.-Ing. degrees in Electrical Engineering from Universitaet Hannover and Universitaet Wuppertal, in 1997 and 2001, respectively. Since 2003, he has worked at Universitas Mercu Buana, Jakarta. He has authored more than 100 publications including three text books: Electromagnetics, Transmission Lines and Antennas. He holds a granted patent and two patent pendings. In 2006 he founded the laboratory Advanced Telecommunication and Applied Electromagnetics in Department of Electrical Engineering at Universitas Mercu Buana. Dr. Alaydrus is Senior Member of IEEE and member of Verein der Deutschen Elektroingenieure (VDE). His current researchs include microwave and millimeter wave components, wireless power transfers, wireless sensor networks, interaction between electromagnetics and materials, and mathematical modeling in signal processing. He is reviewer of several reputable journals including IEEE Trans. On Antennas and Propagation. 